\title{
RELATIONSHIP BETWEEN MODERN PERSONALITY CHARACTERISTICS AND STRESS RESPONSES USING THE SCALE ON WORKING ATTITUDE TYPES (ScWAT)
}

\author{
Toshikazu NOGUCHI
}

Fuculty of Human Sciences, Shimane University, Japan

\begin{abstract}
Changes in the social structure in Japan are leading to gradual changes in the personality of young individuals. These changes, in turn cause changes in adaptation or maladaptation, leading to the emergence of a new type of depression that is different from classical depression. Therefore, the Scale on Working Attitude Types (ScWAT) was developed in the present study, to assess the modern personality characteristics influencing on work. Scale items were developed by identifying the common features of the new type depression and the personality characteristics of young individuals in the modern Japanese society. By analyzing the data of 343 participants in their twenties, 5 subscales were extracted, and the validity and reliability of the scale were confirmed. Clear differences were observed in the personality and stress responses of individuals classified into 5 clusters using this scale. This result suggests that the ScWAT is useful to understand the personality of individuals, to aid stress management.
\end{abstract}

Key words: job stress, modern personality, modern Japanese society

\section{INTRODUCTION}

\section{Change of personality characteristics today}

Several clinical psychology studies have presented different models about the relationship between stressors and stress reactions. French, Rodgers, and Cobb (1974) reported that the disproportion between job demands (complexity, load, and responsibility) and workers' abilities, or that between resources and motivation tend to cause psychological strain (the Person-Environment Fit Model). In other studies, the disproportion between a person and the organization (Kristof, 1996), the gap between job load and a person's discretion in decision making (Karasek \& Theorell, 1990), and the imbalance between required efforts and reward (Siegrist, 1996) were identified as stressors. These studies commonly focused on the imbalance between personal and environmental factors. On the other hand, some studies researched the role of personal factors as mediators in the relationship between stressors and stress reactions.

Lazarus and Folkman (1984) named the conscious cognitive efforts to tackle stressors as "coping," and studied the variation in coping and efficacy. Friedman presented the concept of "Type A personality," and concluded that it was related to the

Correspondence concerning this article should be addressed to Toshikazu Noguchi, Fuculty of Human Sciences, Shimane University, 1060 Nishikawatsu-cho, Matsue, Shimane 690-8504, Japan (e-mail: to4g@yahoo.co.jp). 
incidence of coronary artery disease. In addition to Type A personality, various factors may cause coronary artery disease and mental illnesses, like the degree of anxiety, neurosis, ambiguity tolerance, and family problems (Cooper \& Marashall, 1976). These studies focused on personality characteristics or individuals' inner processes when experiencing stress. In other words, they examined the influence of how people feel, think, and behave in the society.

However, the way individuals feel, think, and behave has changed rapidly in the Japanese society, especially among young individuals. Considering the example of school refusal, Ogura (1982) reported that children exhibiting school refusal tended to be tidy and well behaved, with a good reputation and a strong sense of responsibility. Therefore, their deep sadness, loneliness, anxiety was hidden behind a superficial problem. On the other hand, more recently, Iwamiya (2014) reported that children exhibiting school refusal now tended not to be worried about staying away from school, and that the child in question did not perceive his or her state of "maladaptation."

Considering the example of depression, A typical depressive patient is tidy, faithful, and kind to others, and has a strong sense of responsibility. Such individuals were earlier called as the "melancholic type." On the other hand, since 1990, new type depression has been mainly found among young individuals, and it is called as depression of the immature or dysthymic depression.

This new form of depression is often caused by a trivial rebuke, and patients blame the company for their depressive symptoms, are vigorous outside of the office, or assert that their return to work should be delayed because of illness. This extrapunitive and avoidant personality is different from the personality of an individual with classical depression, who tend to be intrapunitive and impatient to return to work even when he or she may not have recovered sufficiently.

The gradual change in the personality characteristics, mainly among young individuals, is caused by the changes in the social structure. In the Japanese society, the current lifestyle has diversified, and various ways of living are permitted. However, individuals are often in conflict with social demands (Kawai, 2016). Doi (2014) pointed out that because any clear criteria of evaluation have become ineffective and people have lost any general guideline, individuals cannot avoid being sensitive to others' responses and deciding their behavior depending on others' responses. Owing to the situations mentioned above, there has been an increase in the number of individuals who seem to be assertive without conflict or a sense of guilt, who, on the other hand, are sensitive to others' trivial responses. The above examples of changes in school refusal and depression summarize the present changes in the personality and lifestyle of individuals in Japan. However, this is only the tip of the iceberg. This phenomenon is not limited to those who are in bad condition or those who exhibit maladaptation. Therefore, it is important that industrial and occupational mental health consider the modern personality characteristics of employees.

"New type of depression" as a significant feature of personality in our time

In order to consider the modern personality characteristics of employees, a 
questionnaire to assess modern personality characteristics influencing on work will be useful. What aspects should be measured to assess modern personality characteristics? As previously stated, the features of the new type of depression reflects the social structure, and it is related with the personality of young individuals. Therefore, the features of the new type of depression are helpful as reference. However, the knowledge about the new type of depression is generalized from that about pathological depression. Such knowledge may not be appropriate for understanding relatively healthy people. Therefore, in reference to not only the features of the new type of depression but also theories about the current lifestyle, common characteristics between pathological and healthy states need to be extracted for questionnaire development.

Muranaka, Yamakawa, and Sakamoto (2015) abstracted the psychological features of the new type of depression from 14 papers published and analyzed them using the by KJ method. Based on that study, Muranaka, Yamakawa, and Sakamoto (2017) suggested the features of "extreme reactions to evaluation from others," "sensitivity to others" responses," "avoidance," "sense of victimization," "prioritizing oneself," and "intense narcissism" as indicative of the new type of depression. These five factors include all the unique characteristics of the new type of depression, and are expected to summarize the related modern personality characteristics. Therefore, this study referred to these five factors.

"Extreme reaction to evaluation from others" refers to the tendency of being deeply hurt on receiving negative evaluation from others. Does this feature coincide with the personality characteristics of the present youth? Doi (2014) pointed out that the increasing of desire for approval and anxiety around evaluation characterize the young individuals nowadays, and that they feel suffocated with excessive consideration to maintain relationships with friends. This situation is caused by the modern society, in which the sense of values is diversified. Consequently, the existing criteria for evaluation have become ineffective, so individuals cannot avoid being sensitive to others' responses and deciding their behavior depending on others' responses. This instability that stems from expecting others' approval for guiding one's behavior is found not only in the new type of depression but is also the characteristic personality of individuals nowadays. From the above discussion, the significance of measuring desire for approval and anxiety around evaluation is apparent.

"Sensitivity to others' responses" pertains to cautiousness about negative evaluation. It is related to the current tendency of individuals to suppress themselves while being together with someone, because of the excessive consideration assigned to maintaining the relationship with friends, as Doi (2014) pointed out. Thus, by examining the common features among depressed and healthy individuals, the present study attempted to identify questions that could be used to assess individuals' excessive consideration or difficulty in being assertive in relationships.

"Avoidance" refers to the tendency of patients with the new type of depression to avoid their failure, for example in an occupational situation, and to avoid or reject tasks that are perceived as a burden, or tasks they failed on or were criticized about in the past, and the unwillingness to make efforts for any improvement on the performance of such 
tasks. As this phenomenon can be understood as the lack of tolerance or the tendency to be unsatisfied with narcissistic desire, this new type depression is sometimes called as immature depression. Does this type of depression share any features with the modern personality? It is often heard that those in their fifties feel that, contrary to young individuals in the past, the current youth are less responsible and are selfish, and that they work only on the task they like, avoiding tasks they dislike. Kawai (2016) revealed that, in the present Japanese society, individuals have not internalize any social demands into their own mind. Therefore, they experience lesser conflicts between individual desires and social demands. Based on this suggestion, even if an individual is seen as "avoiding" failure or the task he or she dislikes, fundamentally, it should be understood that he or she has lesser responsibilities with reference to the demands from the society. This is the common point between the avoidance behavior of those with the new type of depression and the present general youth. Therefore, the present study measured the avoidance of a difficult of burdensome situation, and of staying these situation.

"Sense of victimization," "prioritizing oneself," and "intense narcissism" fall under the larger concept of "tendency to prioritize oneself" (Muranaka et al., 2015, 2017). This concept refers to the features of selfishness, not being intrapunitive, being punitive toward others or the environment, and being easily displeased if the situation does not match one's wishes. It has already been pointed out that more individuals than before have difficulty in confronting their internal conflicts when encountering sufferings or problems, even if they are healthy and without any serious illness or maladaptation. Additionally, individuals tend to talk about themselves superficially all along, and they only think of events being caused by external factors, for example, by others or the environment (Kawai, 2016; Iwamiya, 2009). This tendency renders it difficult for individuals to think deeply about their own internal factors, which seems to be common with the extrapunitive way of thinking, called as "tendency to prioritize oneself," in the new type of depression. However, it is difficult to measure this feature using a questionnaire because those who are selfish and extrapunitive are often not conscious about their own tendencies. For example, the question "are you selfish?" or "do you often feel that others or the environments are the cause of problems?" may not be valid. We cannot avoid this difficulty if we try to measure "tendency to prioritize oneself" directly. Therefore, the present study measured it as the tendency to want others to exhibit consideration toward oneself. Though this question did not ask about the "tendency to prioritize oneself" directly, young individuals nowadays tend to insist on the lack of consideration from others in the company, and such an assertion is often interpreted by others as "selfishness" or the tendency to "prioritize oneself without reflection." Therefore, the present study measured "need for consideration" as an indicator of "prioritizing oneself."

In addition though it is neither specific to the new type of depression nor to the modern personality, the present study measured "perfectionism." This is a common feature among both classical and the new type of depression, and it is related to Type A personality. This feature is also found in individuals with Autism Spectrum Disorder. Therefore, the present study measured perfectionism as an indicator of possible 
maladaptation.

Based on the above insights derived from the literature, I developed the scale (Scale on Working Attitude Types; ScWAT), which had question items about "desire for approval and anxiety around evaluation," "excessive consideration or difficulty with assertion," "avoidance of difficult or burdensome situations," "need for consideration," and "perfectionism." Furthermore the validity and reliability were examined. In addition, the relationship between stress reaction and the personality types identified by the ScWAT was examined.

\section{Method}

Procedure for developing a tentative scale

I referred to some scales related to these 5 concepts, such as the Martin-Larsen Approval Motivation Scale, Japanese version (Ueda \& Yoshimori, 1990), the Narcissistic Personality Inventory, Japanese short version (NPI-S; Oshio, 1999), the Scale of Over-adaptation in Adolescence (Ishizu, 2006), the Self-oriented Perfectionism Scale (Sakurai \& Ohtani, 1997), and the short version of the Narcissistic Vulnerability Scale (Kamiji \& Miyashita, 2009).

Subsequently, 7 clinical psychologists, including me, who worked in the field of occupational mental health, discussed the 26 questions I developed, examined their validity with reference to actual situations in companies these days, and appropriately revised the expressions of these questions. Based on the opinions of 19 graduate school students of clinical psychology, who were blind to the purpose of this study, we revised the expressions of questions again and thus obtained the final version of the tentative ScWAT.

\section{Survey procedure}

Participants included men and women in their twenties, working in Company A and B, which have about 2000 employees each. They answered the tentative ScWAT using a 5-point Likert scale ranging from

Table 1. Scales in each booklet and the number of valid data

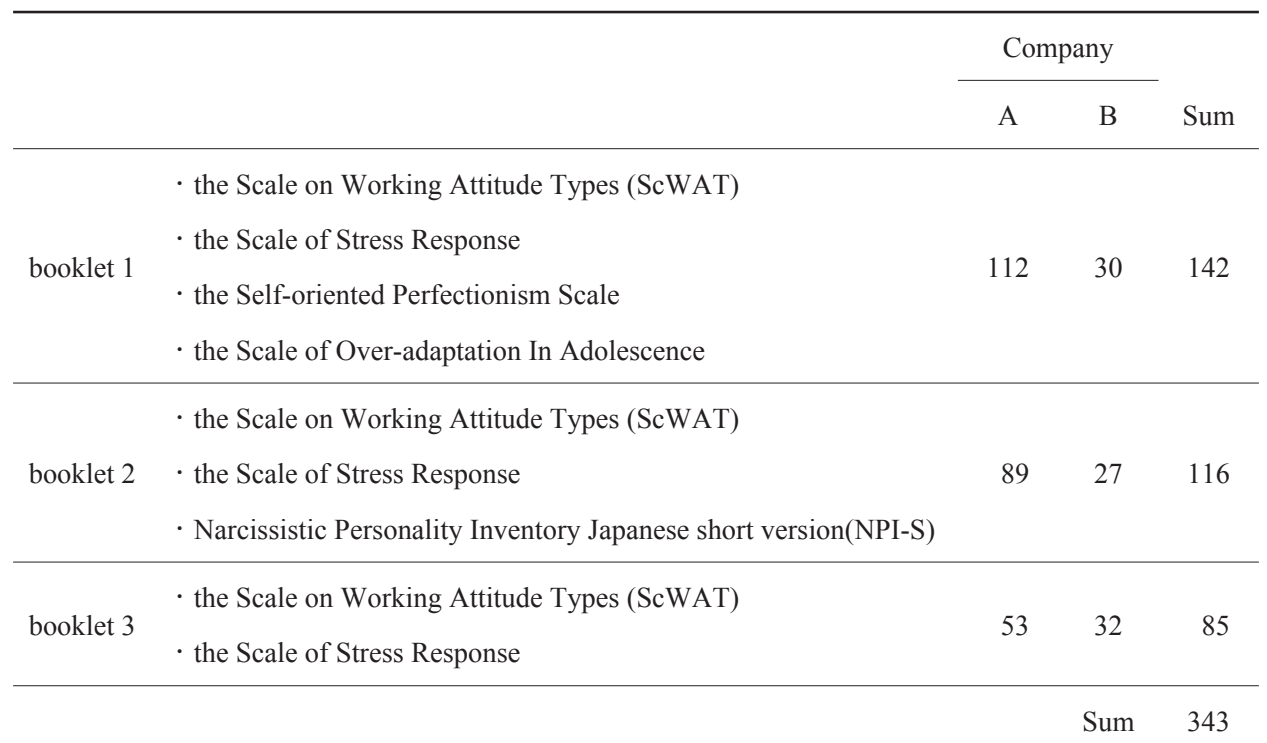


"agree" to "disagree."

To examine the relationship of personality characteristics with stress responses, we asked the participants to answer the Scale of Stress Response (Shimazu, Fuse, Taneichi, Ohashi, \& Kosugi, 1997). Additionally, to verify the concurrent validity of the ScWAT, the Self-oriented Perfectionism Scale (Sakurai \& Ohtani, 1997), the Scale of Over-adaptation in Adolescence (Ishizu, 2006), and the NPI-S (Oshio, 1999) were administered ${ }^{1}$. However, having too many questions in the study questionnaire would increase the burden on subjects, diminishing the reliability of their answers. Therefore, I developed three booklets for the three scales for concurrent validity, and asked each participant to answer any one. The contents of each booklet and the details of the valid data have been presented in Table $1^{2}$.

\section{Results AND Discussion}

\section{Exploratory Factor Analysis}

Table 2 shows the results of the factor analysis on the responses of 343 participants to all 3 pattern booklets (Maximum likelihood method, promax rotation). In total, 5 factors was extracted considering scree, interpretability, and an eigenvalue greater than one as common factors. Further, 6 items were excluded because they had a low factor loading $(<.0 .40)$ or had high factor loadings for some factors. Finally, 20 items were retained in the scale.

The first factor reflected the anxiety that others may think ill of me or dislike me, and was named as the "anxiety of being disliked" factor. The second factor reflected the clear hope for others' consideration, and was named as the "desire for consideration" factor. The third factor reflected the tendency to consider others' convenience and to avoid rejecting others' requests or not being assertive. It was named as the "difficulty with assertion" factor. The fourth factor reflected the tendency to not feel relieved without achieving tasks or completing them, and it was named as the "orientation to perfection" factor. The fifth factor was positively loaded by items relating to the desire to be in charge of an important task, and negatively loaded by items relating to the tendency to avoid responsibility. Specifically, the absolute value of the latter loading (-.70 and $-.61)$ was higher than the former (.54 and .36); therefore, it seemed to be important for this factor whether individuals want to assume or avoid responsibility. Thus, it was named as the "preference to responsibility."

\section{Reliability}

After the variables with the negative loadings were reverse scored, the scores on the items of each factor were summed. Each score was regarded as the measure of each factor. Table 3 shows the descriptive statistics for each factor, including the Cronbach's alpha and average inter-item correlation. The results confirmed adequate reliability of the ScWAT, as evidenced by a Cronbach's alpha of over 0.70 for each factor (though they comprised only 4 items ${ }^{3}$ ). Additionally, the average inter-item correlation was good

\footnotetext{
1 The Self-oriented Perfectionism Scale was a 6-point scale, while the Stress Response Scale, Scale of Over-adaptation for Adolescence, and the Narcissistic Personality Inventory were 5-point scales.

${ }^{2}$ Though 4 more scales were used simultaneously, I had to omit them from this paper for want of space.

${ }^{3}$ The higher the number of items in the scale, the higher the Cronbach's alpha tended to be.
} 
Table 2. Factor analysis of the Scale on Working Attitude Types. (n=343, Maximum likelihood method, promax rotation)

\begin{tabular}{|c|c|c|c|c|c|c|}
\hline question & $\mathrm{F} 1$ & $\mathrm{~F} 2$ & F3 & F4 & F5 & Communality \\
\hline $\begin{array}{l}\text { I am anxious about whether others may think ill of } \\
\text { me }\end{array}$ & .82 & -.04 & .06 & .01 & .10 & .69 \\
\hline $\begin{array}{l}\text { I sometimes want to stop worrying about whether } \\
\text { someone may hate me }\end{array}$ & .80 & -.05 & .05 & -.04 & .05 & .63 \\
\hline $\begin{array}{l}\text { I am often anxious about whether someone may } \\
\text { lose interest in me }\end{array}$ & .60 & .17 & -.03 & -.02 & .00 & .49 \\
\hline $\begin{array}{l}\text { I sometimes ponder later about whether I might } \\
\text { have been boastful }\end{array}$ & .53 & -.09 & -.11 & .06 & -.10 & .20 \\
\hline Sometimes I want consideration for me & -.05 & .81 & -.03 & .07 & .03 & .61 \\
\hline $\begin{array}{l}\text { I want others to understand my feelings or } \\
\text { perspective adequately }\end{array}$ & -.02 & .71 & .05 & -.07 & .05 & .51 \\
\hline $\begin{array}{l}\text { Sometimes others around me don't show enough } \\
\text { consideration toward me }\end{array}$ & -.11 & .60 & -.05 & .02 & -.08 & .30 \\
\hline $\begin{array}{l}\text { I feel unsatisfied if I do not receive approval or } \\
\text { appreciation from others }\end{array}$ & .20 & .52 & -.01 & -.03 & .07 & .43 \\
\hline I often respect others' convenience & -.16 & .09 & .73 & .04 & -.10 & .50 \\
\hline I feel guilty if I reject others' request & -.03 & -.09 & .71 & -.03 & .15 & .43 \\
\hline $\begin{array}{l}\text { It is difficult for me to assert my preferences when } \\
\text { they are contrary to those of others }\end{array}$ & .05 & -.06 & .62 & -.02 & -.16 & .48 \\
\hline I always consider others' wishes & .23 & .03 & .54 & .03 & .01 & .50 \\
\hline $\begin{array}{l}\text { It is difficult for me to leave a task incomplete } \\
\text { when I'm in charge }\end{array}$ & .11 & -.02 & .00 & .69 & -.03 & .46 \\
\hline I dislike letting things pass without notice & .06 & .07 & -.15 & .64 & -.06 & .41 \\
\hline I am not satisfied unless I achieve a goal assigned & .00 & -.08 & .06 & .62 & .08 & .43 \\
\hline I tackle a troublesome problem patiently & -.15 & .04 & .12 & .56 & .10 & .38 \\
\hline I want to be trusted to complete responsible tasks & -.07 & .11 & .04 & .07 & .72 & .55 \\
\hline $\begin{array}{l}\text { I want to exhibit spectacular performance on the } \\
\text { job }\end{array}$ & .19 & .07 & -.03 & -.02 & .71 & .52 \\
\hline $\begin{array}{l}\text { I tend to be under a lot of pressure in situations in } \\
\text { which I am responsible }\end{array}$ & .31 & .13 & .03 & .07 & -.54 & .49 \\
\hline \multirow[t]{8}{*}{ If possible, I want to avoid any pressure or burden } & -.01 & .18 & .07 & -.08 & -.44 & .29 \\
\hline & 3.51 & 2.90 & 2.75 & 1.92 & 2.08 & 13.16 \\
\hline & \multicolumn{6}{|c|}{ inter-factor correlations } \\
\hline & 1.00 & & & & & \\
\hline & .59 & 1.00 & & & & \\
\hline & .55 & .30 & 1.00 & & & \\
\hline & -.02 & .00 & -.03 & 1.00 & & \\
\hline & -.09 & -.11 & -.24 & .39 & .00 & \\
\hline
\end{tabular}


Table 3. Descriptive statistics for each factor and reliability

\begin{tabular}{lrccc}
\hline & M & SD & Cronbach's alpha & $\begin{array}{c}\text { average inter-item } \\
\text { correlation }\end{array}$ \\
\hline Anxiety of being disliked & 10.18 & 2.84 & 0.77 & $0.47^{* *}$ \\
Desire for consideration & 9.06 & 2.48 & 0.75 & $0.46^{* *}$ \\
Difficulty with assertion & 11.91 & 2.40 & 0.76 & $0.44^{* *}$ \\
Orientation to perfection & 11.14 & 2.23 & 0.77 & $0.42^{* *}$ \\
Preference to responsibility & 9.38 & 2.48 & 0.7 & $0.43^{* *}$ \\
\hline
\end{tabular}

Note. $\mathrm{n}=343 . * * p<.01$

for each factor.

\section{Factorial validity}

A confirmatory factor analysis was conducted using Amos 24.0. The maximum likelihood method was used for parameter estimation. For model identification, loadings per factor and paths from error variances to observed variances were fixed to one. To confirm the adequacy of the model, the following indexes were referred: Goodness of Fit Index (GFI), Adjusted Goodness of Fit Index (AGFI), Comparative Fit Index (CFI) and Root Mean Square Error of Approximation (RMSEA).

First, the model was tested, in which all items from the same questionnaire loaded onto the same factor and the covariance between each factor was assumed; GFI $=.897$, $\mathrm{AGFI}=.865, \mathrm{CFI}=.885, \mathrm{RMSEA}=.064$. Further, the correlations between Factor 1 and 2, Factor 2 and 3, and Factor 2 and 4 were not significant. Therefore, the second model was tested (Fig. 1) ${ }^{4}$, in which these three correlations were assumed as 0 and some correlations were assumed between error variances with reference to the index for adjustment; GFI $=.936$, AGFI $=.909$, CFI $=.949$, RMSEA $=.044$. All the path coefficients were significant $(p<.001)$. Thus, the second model had sufficient adequacy and was more adequate than the first one.

\section{Concurrent validity}

Pearson's correlations were calculated to examine the relationship of the five subscales of the ScWAT with the Self-oriented Perfectionism Scale (Sakurai \& Ohtani, 1997) and the Scale of Over-adaptation in Adolescence (Ishizu, 2006) in Booklet A (n = 142), and between the five sub-scales of the ScWAT and the NPI-S (Oshio, 1999; $\mathrm{n}=$ 116; Table 4, 5, and 6).

The ScWAT measure of "anxiety of being disliked" was highly correlated with "the effort to respond to others' expectation" in the Scale of Over-adaptation in Adolescence $(\mathrm{r}=.71)$. There was no significant correlation between the desire for approval in the NPI-S, which showed that this measure was related to the tendency to avoid being

\footnotetext{
${ }^{4}$ Paths of error correlations are omitted in Fig.1.
} 


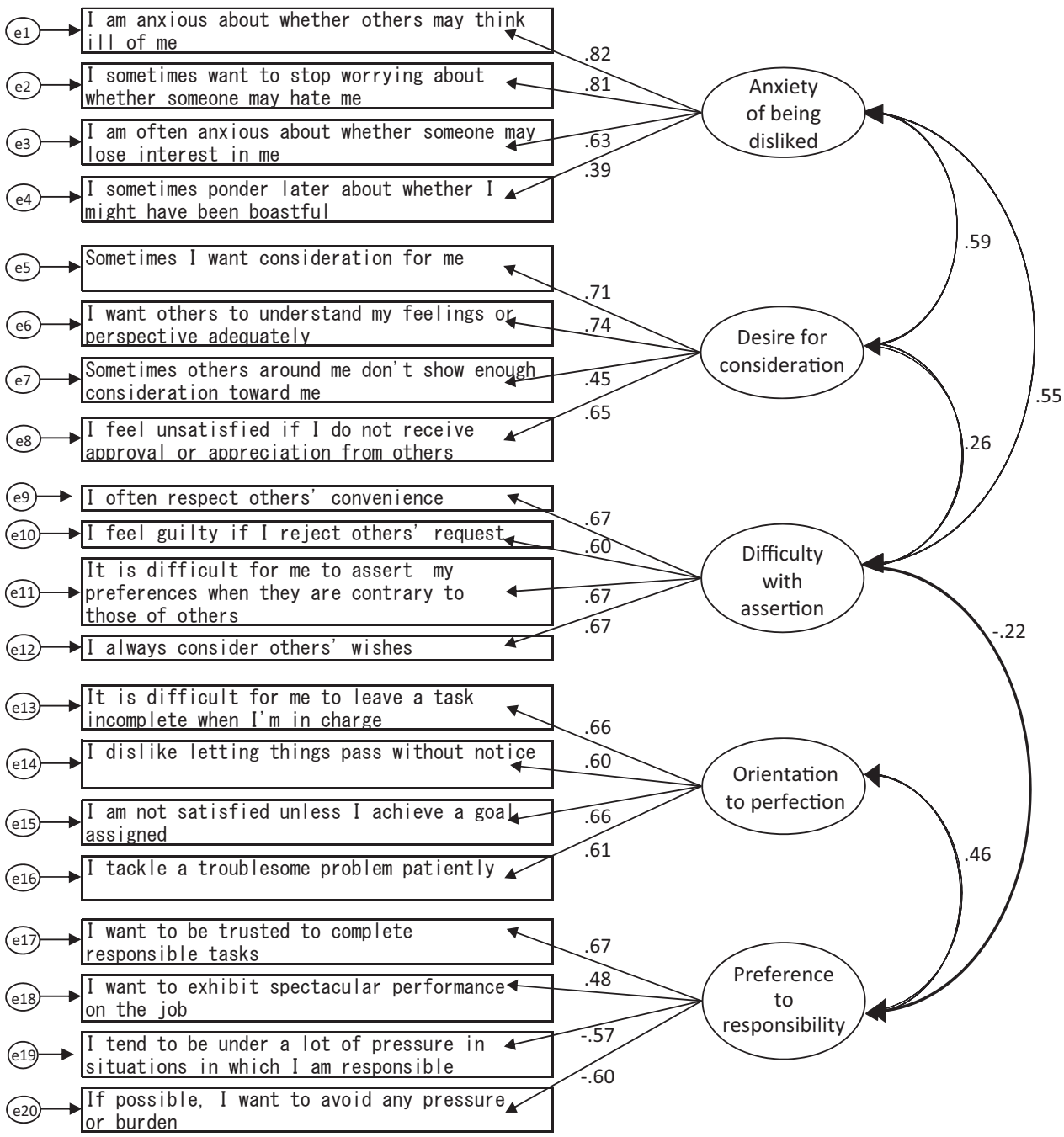

Fig. 1. Result of a confirmatory factor analysis

thought ill of by others rather than of wanting their approval.

The ScWAT measure of "desire for consideration" was correlated with "the effort to respond to others' expectation" in the Scale of Over-Adaptation in Adolescence $(r=.54)$ and it had a weak correlation with the desire to be perfect and excessive focus on his or her failure on the Self-oriented Perfectionism Scale. These findings indicated that the ScWAT measure of "desire for consideration" reflected the tendency to cope in a dependent and extrapunitive manner, with a sense of guilt or impotence.

The ScWAT measure of "difficulty with assertion" was optimally or highly correlated with each subscale of the Scale of Over-adaptation in Adolescence, and it was especially high for "self-suppression." It was negatively correlated with the "self- 
Table 4. Pearson's correlations with the Scale of Over-adaptation in Adolescence

\begin{tabular}{lccccc}
\hline & $\begin{array}{c}\text { Effort to respond to } \\
\text { others' expectation }\end{array}$ & $\begin{array}{c}\text { Self- } \\
\text { suppression }\end{array}$ & $\begin{array}{c}\text { Sense of self- } \\
\text { insufficiency }\end{array}$ & $\begin{array}{c}\text { Consideration } \\
\text { for others }\end{array}$ & $\begin{array}{c}\text { Total score of } \\
\text { over-adaptation }\end{array}$ \\
\hline $\begin{array}{l}\text { Anxiety of being } \\
\text { disliked }\end{array}$ & $.71^{* *}$ & .12 & $.27^{* *}$ & $.30^{* *}$ & $.55^{* *}$ \\
$\begin{array}{l}\text { Desire for } \\
\text { consideration }\end{array}$ & $.54^{* *}$ & .11 & $.22^{* *}$ & $.25^{* *}$ & $.43^{* *}$ \\
$\begin{array}{l}\text { Difficulty with } \\
\text { assertion }\end{array}$ & $.51^{* *}$ & $.62^{* *}$ & $.42^{* *}$ & $.42^{* *}$ & $.69^{* *}$ \\
$\begin{array}{l}\text { Orientation to } \\
\text { perfection }\end{array}$ & $.24^{* *}$ & -.10 & -.022 & $.40^{* *}$ & $.19^{*}$ \\
$\begin{array}{l}\text { Preference to } \\
\text { responsibility }\end{array}$ & .10 & $-.20^{*}$ & $-.41^{* *}$ & .08 & -.11 \\
\hline
\end{tabular}

Note. $\mathrm{n}=142 . * p<.05, * * p<.01$

Table 5. Pearson's correlations with the Scale of Self-oriented Perfectionism

\begin{tabular}{lccccc}
\hline & $\begin{array}{c}\text { Desire to be } \\
\text { perfect }\end{array}$ & $\begin{array}{c}\text { Tendency to } \\
\text { set high goals }\end{array}$ & $\begin{array}{c}\text { Excessive } \\
\text { focus on his } \\
\text { or her failure }\end{array}$ & $\begin{array}{c}\text { Tendency not to } \\
\text { have confidence in } \\
\text { his or her behavior }\end{array}$ & $\begin{array}{c}\text { Total score of } \\
\text { self-oriented } \\
\text { perfectionism }\end{array}$ \\
\hline $\begin{array}{l}\text { Anxiety of being } \\
\text { disliked }\end{array}$ & $.18^{*}$ & $.21^{*}$ & $.28^{* *}$ & .15 & $.28^{* *}$ \\
$\begin{array}{l}\text { Desire for } \\
\text { consideration }\end{array}$ & $.28^{* *}$ & .08 & $.35^{* *}$ & .11 & $.31^{* *}$ \\
$\begin{array}{l}\text { Difficulty with } \\
\text { assertion } \\
\begin{array}{l}\text { Orientation to } \\
\text { perfection }\end{array}\end{array}$ & .04 & .09 & $.25^{* *}$ & $.20^{*}$ & $.19^{*}$ \\
$\begin{array}{l}\text { Preference to } \\
\text { responsibility }\end{array}$ & $.61^{* *}$ & $.35^{* *}$ & .08 & $.19^{*}$ & $.44^{* *}$ \\
\hline
\end{tabular}

Note. $\mathrm{n}=142 . * p<.05, * * p<.01$

Table 6. Pearson's correlations with the Narcissistic Personality Inventory, Japanese short version

\begin{tabular}{lcccc}
\hline & $\begin{array}{c}\text { Sense of } \\
\text { superiority and } \\
\text { competence }\end{array}$ & $\begin{array}{c}\text { Desire to be } \\
\text { outstanding and to } \\
\text { be approved }\end{array}$ & $\begin{array}{c}\text { Self-assertiveness } \\
\text { Total score of } \\
\text { NPI-S }\end{array}$ \\
\hline $\begin{array}{l}\text { Anxiety of being } \\
\text { disliked }\end{array}$ & -.12 & .17 & $-.19 *$ & -.04 \\
$\begin{array}{l}\text { Desire for } \\
\text { consideration }\end{array}$ & .12 & $.29 * *$ & -.09 & .14 \\
$\begin{array}{l}\text { Difficulty with } \\
\text { assertion } \\
\begin{array}{l}\text { Orientation to } \\
\text { perfection }\end{array}\end{array}$ & $-.19^{*}$ & -.019 & $-.40^{* *}$ & $.23^{*}$ \\
$\begin{array}{l}\text { Preference to } \\
\text { responsibility }\end{array}$ & .00 & $.22^{*}$ & $.20^{* *}$ \\
\hline
\end{tabular}

Note. $\mathrm{n}=116 . * p<.05, * * p<.01$ 
assertiveness" score on the NPI-S. These findings indicated that the ScWAT measure of "difficulty with assertion" adequately measured the tendency to exhibit consideration for others, self-suppression, and difficulty with assertion.

The ScWAT measure of "orientation to perfection" was correlated strongly with the score on "desire to be perfect," and optimally with the tendency to set high goals for oneself according to the Self-oriented Perfectionism Scale. These findings showed that the ScWAT measure of "orientation to perfection" measured the desire to be or to become perfect.

The ScWAT measure of "preference to responsibility" was negatively correlated with the "sense of self-insufficiency" in the Scale of Over-adaptation in Adolescence, and it was positively correlated with each score on the NPI-S, especially with that on the desire to be outstanding and to be approved. These findings showed that the measure of "preference to responsibility" assessed the positive aspect of the desire for approval, especially the desire to be outstanding or to be approved, in contrast with the measure of "anxiety of being disliked," which measured the negative aspect of the same.

Thus, the above results confirmed that the five measures of the ScWAT had optimal validity.

\section{Classification with cluster analysis}

The 343 participants were classified across the five measures of the ScWAT using Ward's hierarchical cluster analysis (Square Euclidean distance).

From the Dendrogram, the valid number of clusters seemed to be 4 or 5 . Based on the findings of comparing the means and SDs of the 5 measures in the case of 4 clusters with those in the case of 5 clusters, the classification into 5 clusters was adopted, referring to interpretability. Table 7 and Fig. 2 shows the $Z$ scores in which averages were adjusted to 0 and SDs were adjusted to 1 in each cluster.

Cluster 1 included the following features: high "desire for consideration" and "preference to responsibility," and low "anxiety of being disliked," "difficulty with assertion," and "orientation to be perfect." Thus, individuals in Cluster 1 seemed to want to be dealt with much care and to be approved, as opposed to those in Cluster 3, who tended to reflect about oneself and tended to feel anxious or to suppress oneself. Therefore, Cluster 1 was named as the "approval desiring" type.

Cluster 2 included the following features: interpersonal anxiety and dissatisfaction were extremely low, but they aimed to achieve goals or complete their tasks perfectly. Therefore, this cluster was labelled as the "completion oriented" type.

Cluster 3 included the following features: having low confidence, as evidenced by high "anxiety of being disliked" and "difficulty with assertion," and simultaneously exhibiting extrapunitive tendencies, as evidenced by the high "desire for consideration." People in this cluster seemed to have strong interpersonal anxiety but they wanted to fulfill others' expectation as well. Therefore, it was named as the "concerned with evaluation" type.

The features of Cluster 4 included the following: extremely high "preference to responsibility" and high "orientation to be perfect," and low on other measures. Thus, 
Table 7. Zscores for each cluster

\begin{tabular}{lccccc}
\hline & Cluster 1 & Cluster 2 & Cluster 3 & Cluster 4 & Cluster 5 \\
\hline Anxiety of being disliked & -0.01 & -1.00 & 1.19 & -0.13 & 0.41 \\
Desire for consideration & 0.49 & -0.80 & 1.15 & -0.48 & 0.00 \\
Difficulty with assertion & -0.23 & -0.53 & 0.74 & -0.29 & 0.48 \\
Orientation to perfection & -0.29 & 0.24 & 0.54 & 0.56 & -0.66 \\
Preference to responsibility & 0.24 & 0.00 & -0.05 & 1.46 & -1.04 \\
\hline
\end{tabular}

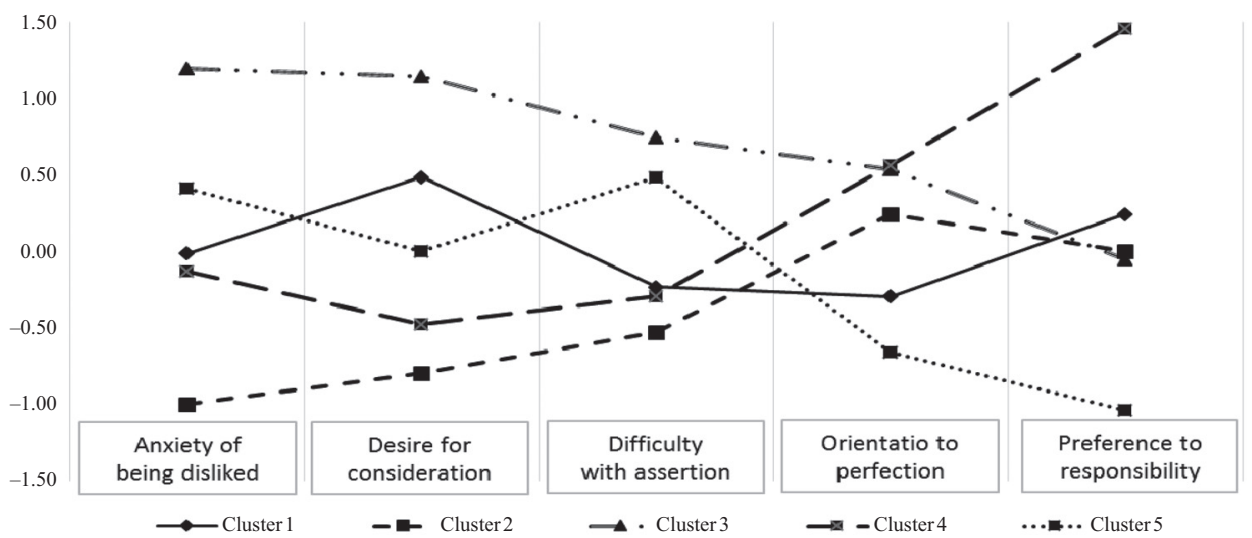

Fig. 2. Graph of Zscores for each cluster

individuals belonging to Cluster 4 seemed to be in a stable relationship with others and they aimed to succeed in their job. Therefore, this cluster was named as the "desiring achievement" type.

Cluster 5 included the following features: having high "anxiety of being disliked" and "difficulty with assertion," but the tendency to avoid responsibility was evidenced by the low "orientation to be perfect" and "preference to responsibility." Therefore, this cluster was labelled as the "avoiding responsibility" type.

\section{Clusters and differences between sexes}

Table 8 shows the ratio of sexes in each cluster. A chi-square analysis indicated significant gender-based differences in each cluster; $\chi^{2}=13.88$, df $=4, p<.01$. A residual analysis indicated that Cluster 1 and 4 included more men than women $(p<.05)$, and Cluster 5 comprised more women than men $(p<.05$; Table 9). Further, men tended to exhibit a higher "preference to responsibility" as compared to women. This result suggests that men tend to be expected to assume an important role in Japanese companies more often than women are. However, further consideration will be needed about the factor of company culture or local color. 
Table 8. Ratio of sexes in each cluster

\begin{tabular}{cccc}
\hline & Male & Female & Total \\
\hline Cluster 1 & $46(64 \%)$ & $26(36 \%)$ & $72(100 \%)$ \\
Cluster 2 & $46(52 \%)$ & $42(48 \%)$ & $88(100 \%)$ \\
Cluster 3 & $23(45 \%)$ & $28(55 \%)$ & $51(100 \%)$ \\
Cluster 4 & $34(69 \%)$ & $15(31 \%)$ & $49(100 \%)$ \\
Cluster 5 & $35(42 \%)$ & $48(58 \%)$ & $83(100 \%)$ \\
\hline Total & 184 & 159 & 343
\end{tabular}

Table 9. Result of a residual analysis

\begin{tabular}{ccc}
\hline & Male & Female \\
\hline Cluster 1 & $+1.96^{*}$ & $-1.96^{*}$ \\
Cluster 2 & +0.30 & -0.30 \\
Cluster 3 & -1.33 & +1.33 \\
Cluster 4 & $+2.39 *$ & $-2.39^{*}$ \\
Cluster 5 & $-2.41^{*}$ & $+2.41^{*}$ \\
\hline
\end{tabular}

$* p<.05$

\section{Relationships among clusters and stress responses}

A one-way analysis of variance (ANOVA) was conducted to compare the effects of the type of clusters on the scores on the subscales (melancholic, irritated, somatic stress response, nervous, and tired) of the Stress Response Scale. Findings revealed that the main effects of the type of clusters were significant for melancholic feelings $(F(4,338)=$ $26.30, p<.01)$, irritated feelings $(F(4,338)=23.00, p<.01)$, somatic stress response $(F$ $(4,338)=10.00, p<.01)$, nervous feelings $(F(4,338)=23.55, p<.01)$, and tired feelings $(F(4,338)=9.89, p<.01)$. The Levene test for Equality of Variances showed that the variances for melancholic feelings, irritated feelings, and somatic stress response were not equal (each $p<.01$ ); therefore, the Welch method was used for the analyses. Accordingly, the adjusted degrees of freedom were 154.55 (melancholic), 152.493 (irritated), and 156.91 (somatic stress response), and the results of the ANOVAs were all significant (each $p<.01$ ). Table 10 shows the results of the ANOVAs. The Tukey's multiple comparison test (HSD test) or the Dunnett T3 test was conducted when the variances were not equal. Table 11 shows the results of multiple comparison. Fig. 3 shows the Z scores for the Stress Response Scale scores in each cluster.

The stress responses were normal in Cluster 1, low in Cluster 2, extremely high in Cluster 3, extremely low in Cluster 4, and high in Cluster 5.

Generally, stress responses seemed to be strong in those who had the tendency to be 
Table 10. Results of the ANOVAs: relationships among clusters and stress responses

\begin{tabular}{ccccccccccccc}
\hline & $\begin{array}{c}\text { Cluster 1 } \\
\mathrm{n}=72\end{array}$ & \multicolumn{2}{c}{$\begin{array}{c}\text { Cluster 2 } \\
\mathrm{n}=88\end{array}$} & \multicolumn{2}{c}{$\begin{array}{c}\text { Cluster 3 } \\
\mathrm{n}=51\end{array}$} & \multicolumn{2}{c}{$\begin{array}{c}\text { Cluster 4 } \\
\mathrm{n}=49\end{array}$} & \multicolumn{2}{c}{$\begin{array}{c}\text { Cluster 5 } \\
\mathrm{n}=83\end{array}$} \\
& $\mathrm{M}$ & $\mathrm{SD}$ & $\mathrm{M}$ & $\mathrm{SD}$ & $\mathrm{M}$ & $\mathrm{SD}$ & $\mathrm{M}$ & $\mathrm{SD}$ & $\mathrm{M}$ & $\mathrm{SD}$ & $\mathrm{F}$ \\
Melancholic & 17.44 & 5.17 & 16.47 & 5.93 & 21.69 & 7.14 & 12.33 & 4.72 & 21.57 & 5.88 & $26.299^{* *}$ \\
Irritated & 14.04 & 4.15 & 11.28 & 4.10 & 17.61 & 5.91 & 10.02 & 4.00 & 14.52 & 5.07 & $22.996^{* *}$ \\
$\begin{array}{c}\text { Somatic stress } \\
\text { response }\end{array}$ & 10.26 & 3.91 & 8.85 & 4.27 & 12.02 & 5.41 & 7.35 & 2.81 & 10.89 & 4.60 & $9.956^{* *}$ \\
Nervous & 15.10 & 4.05 & 12.69 & 4.56 & 17.14 & 4.95 & 10.86 & 4.19 & 17.08 & 4.48 & $23.548^{* *}$ \\
Tired & 12.10 & 2.97 & 11.30 & 3.78 & 12.86 & 3.88 & 9.94 & 3.21 & 13.46 & 3.26 & $9.888^{* *}$ \\
\hline
\end{tabular}

$* * p<.01$

concerned about others' responses, like "anxiety of being disliked" or "difficulty with assertion," and among those not having high "preference to responsibility." On the other hand, stress responses seemed to be weak among those with a relatively higher level of "preference to responsibility" than the tendency to be concerned about others' response. These results suggest that the ability to have an inner yardstick for setting a goal leads individuals to be independent from others' responses and impart tolerance to some stressors.

Further, irritated feelings were extremely high in individuals in Cluster 3. As such individuals hope to fulfill others' expectations to receive their approval as well as are concerned about others' evaluation. Therefore, they may experience high levels of anxiety. This tendency is, so to speak, active concerning others' opinions, which leads to desire for consideration from others and irritation toward them. In contrast to individuals in Cluster 3, those in Cluster 5 were concerned about others, but they did so passively, without wanting to stand out. They did not want something from others, but rather, they were only anxious about what effect their own behavior would have on others, like inviting their rejection. Therefore, nervous feelings were strong in individuals in Cluster 5 .

In Cluster 2 and 4, the stress responses were generally lower. However, somatic stress responses and tired feelings seemed to be high among the 5 subscales of ScWAT. These results suggest that stress responses may be expressed as somatic rather than psychological responses. This point needs to be further explored in future studies.

\section{CONCLUSIONS}

A scale was developed in the present study, to assess the way modern personality factors influence work (ScWAT). The validity and reliability of this scale were optimal. This scale classified the present sample into 5 clusters, which showed the clear differences in personality characteristics and stress responses. The present findings 
Table 11. Results of multiple comparison

Melancholic

\begin{tabular}{|c|c|c|c|c|c|}
\hline & Cluster 1 & Cluster 2 & Cluster 3 & Cluster 4 & Cluster 5 \\
\hline \multicolumn{6}{|l|}{ Cluster 1} \\
\hline Cluster 2 & n.s & & & & \\
\hline Cluster 3 & * & $*$ & & & \\
\hline Cluster 4 & * & $*$ & * & & \\
\hline Cluster 5 & * & $*$ & n.s & $*$ & \\
\hline \multicolumn{6}{|c|}{ Irritated } \\
\hline & Cluster 1 & Cluster 2 & Cluster 3 & Cluster 4 & Cluster 5 \\
\hline \multicolumn{6}{|l|}{ Cluster 1} \\
\hline Cluster 2 & * & & & & \\
\hline Cluster 3 & $*$ & $*$ & & & \\
\hline Cluster 4 & * & n.s & $*$ & & \\
\hline Cluster 5 & n.s & $*$ & * & $*$ & \\
\hline
\end{tabular}

Somatic stress response

\begin{tabular}{|c|c|c|c|c|c|}
\hline & Cluster 1 & Cluster 2 & Cluster 3 & Cluster 4 & Cluster 5 \\
\hline \multicolumn{6}{|l|}{ Cluster 1} \\
\hline Cluster 2 & n.s & & & & \\
\hline Cluster 3 & n.s & $*$ & & & \\
\hline Cluster 4 & * & n.s & $*$ & & \\
\hline Cluster 5 & n.s & $*$ & n.s & $*$ & \\
\hline \multicolumn{6}{|c|}{ Nervous } \\
\hline & Cluster 1 & Cluster 2 & Cluster 3 & Cluster 4 & Cluster 5 \\
\hline \multicolumn{6}{|l|}{ Cluster 1} \\
\hline Cluster 2 & $*$ & & & & \\
\hline Cluster 3 & n.s & $*$ & & & \\
\hline Cluster 4 & $*$ & n.s & * & & \\
\hline Cluster 5 & $*$ & $*$ & n.s & $*$ & \\
\hline \multicolumn{6}{|c|}{ Tired } \\
\hline & Cluster 1 & Cluster 2 & Cluster 3 & Cluster 4 & Cluster 5 \\
\hline \multicolumn{6}{|l|}{ Cluster 1} \\
\hline Cluster 2 & n.s & & & & \\
\hline Cluster 3 & $*$ & n.s & & & \\
\hline Cluster 4 & n.s & n.s & $*$ & & \\
\hline Cluster 5 & n.s & $*$ & n.s & $*$ & \\
\hline
\end{tabular}

$* p<.05$ 


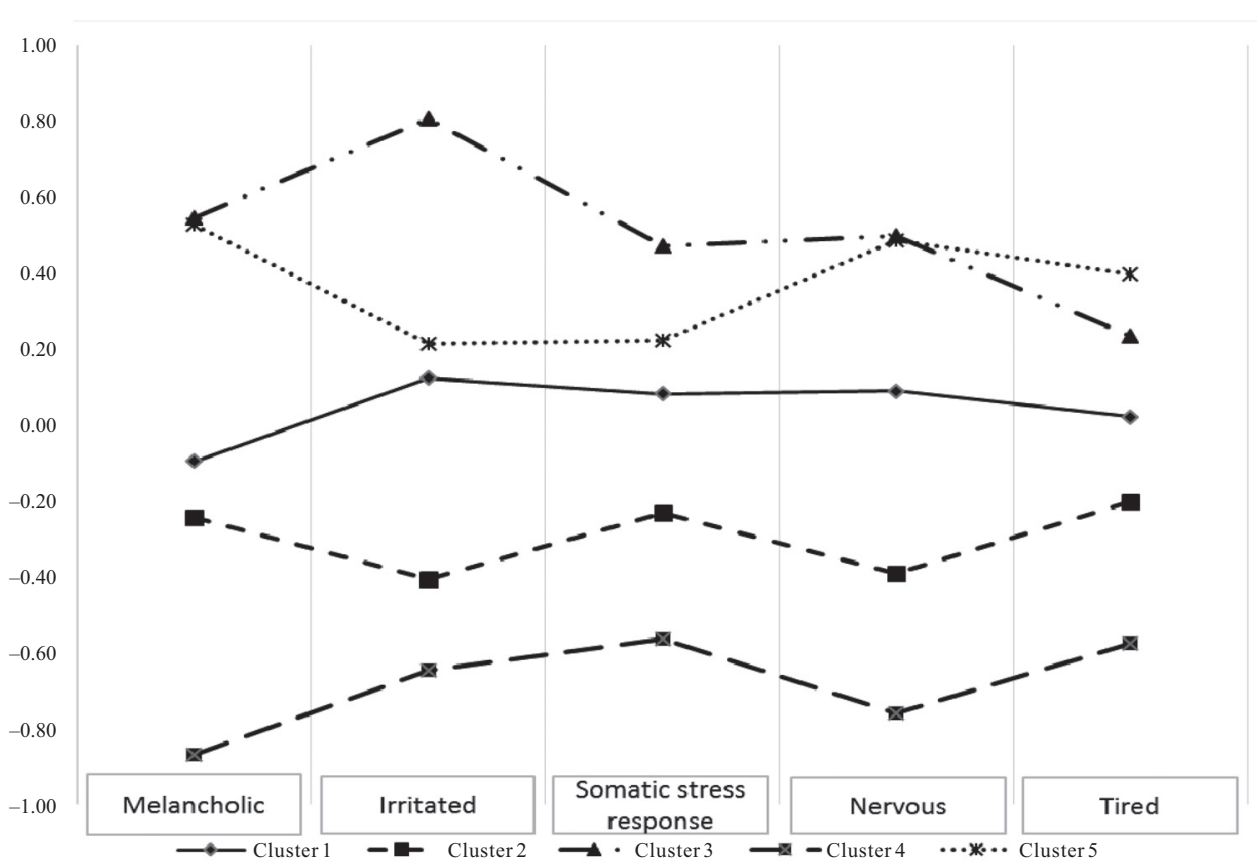

Fig. 3. Z scores for the Stress Response Scale scores in each cluster.

suggest that the ScWAT may be useful for understanding employees' personalities to aid stress management. Specifically, it is impressive that the cluster of avoidance of responsibility was abstracted, and it was found to be related to higher stress responses as compared to individuals who tend to be eager and perfectionistic. It is suggested to interpret the discrepancy found in the characteristics of the present Japanese society and the tendency to avoid common tasks in schooldays in the past in terms of individual considerations, and based on the fact that people are suddenly expected to exhibit initiative and responsibility at work.

\section{REFERENCES}

Cooper, C. L., \& Marashall, J. 1976. Occupational sources of stress: A review of the literature relating to coronary heart disease and mental ill health. Journal of Occupational and Organizational Psychology, 49, 11-28.

Doi, T. 2014. Tsunagari wo aorareru kodomotachi [Children are urged to relationships]. Tokyo, Japan: Iwanami Shoten.

French, J. R. P., Rodgers, W. L., \& Cobb, S. 1974. Adjustment as person-environment fit. In G. Coelho, D. Hamburg, \& J. Adams, (Eds.), Coping and adaptation (pp. 316-333). New York, NY: Basic Books.

Kamiji, Y., \& Miyashita, K. 2009. Narcissistic vulnerability, self-discrepancy, and self-esteem as predictors of propensity for social phobia. Japanese Journal of Personality, 17(3), 280-291.

Karasek, R., \& Theorell, T. 1990. Healthy work: Stress, productivity, and the reconstruction of working life. New York, NY: Basic Books. 
Kawai, T. 2016. Hattatsushougai no zouka to hattatsu no hiteikeika [Increase of developmental disorder and atypicalization of mental development]. In T. Kawai \& Y. Tanaka, (Eds.), Hattatsu no hiteikeika to shinriryouhou [Atypicalization of mental development and psychotherapy] (pp. 4-24). Osaka, Japan: Sogensha.

Kristof, A. L. 1996. Person-organization fit: An integrative review of its conceptualizations, measurement, and implications. Personnel Psychology, 49(1), 1-49.

Lazarus, R. S., \& Folkman, S. 1984. Stress, appraisal, and coping. New York, NY: Springer.

Ishizu, K. 2006. Development of a scale of over-adaptation. Proceedings of the Japanese Association of Counseling Science, 29, 137.

Iwamiya, K. 2009. Futsu no ko no shishunki ["Normal" adolescence]. Tokyo, Japan: Iwanami Shoten.

Iwamiya, K. 2014. Gendai no ishiki to "monogatari" [Modern Consciousness and "narrative"]. Kokoro no kagaku [Human Mind] (vol. 175, pp. 81-87) Tokyo, Japan: Nippon Hyoronsha.

Muranaka, M., Yamakawa, I., \& Sakamoto, S. 2015. Senmonka ha shingata utsu wo donoyouni toraeteiruka [How do mental health specialists understand "Modern-Type Depression"]. Psychological research, Nihon University, 36, 44-51.

Muranaka, M., Yamakawa, I., \& Sakamoto, S. 2017. Taijinkabin/ jikoyuusennshakudo no sakusei: Shingata utsu no shinrigakutekitokuchou no sokutei [Development of the Interpersonal Sensitivity/ Priviledged Self Scale: The measurement of a psychological characteristic related to "Modern-Type Depression"]. Japanese Journal of Psychology, 87(6), 622-632.

Ogura, K. 1982. Toukou kyohi [School Refusal]. In Y. Yamanaka (Ed.), Mondai koudou [Problematic behavior] (pp. 19-41). Tokyo, Japan: Nihon Bunka Kagakusha.

Oshio, A. 1999. Narcissistic tendency and friendship in high school students. Japanese Journal of Personality, 8(1), 1-11.

Sakurai, S., \& Ohtani, Y. 1997. Relations of "self-oriented perfectionism" to depression and hopelessness. The Japanese Journal of Psychology, 68(3), 179-186.

Shimazu, A., Fuse, M., Taneichi, K., Ohashi, Y., \& Kosugi, S. 1997. Jugyouin wo taishou toshita stress chousahyou sakusei no kokoromi [Development of a job stressor and stress reactions scale for employees]. Job Stress Research, 4(1), 41-52.

Siegrist, J. 1996. Adverse health effects of high-effort/low-reward conditions. Journal of Occupational Health Psychology, 1(1), 27-41.

Ueda, M., \& Yoshimori, M. 1990. Nihon ban MLAM syounin yokkyuu syakudo sakusei no kokoromi [Development of a Japanese version of the Martin-Larsen Approval Motivation (MLAM) Scale]. Bulletin of Faculty of the Education, Hiroshima University, Part 1, 39, 151-156.

(Manuscript received 31 August, 2018; Revision accepted 27 December, 2018; Released online in J-STAGE as advance publication 5 September, 2019) 